American Journal of Applied Sciences 7 (5): 711-716, 2010

ISSN 1546-9239

(C) 2010Science Publications

\title{
Development of Empirical Prediction Formula for Penetration of Ogive Nose Hard Missile into Concrete Targets
}

\author{
${ }^{1}$ Ahmad Mujahid Ahmad Zaidi, ${ }^{2}$ Qadir Bux Alias Imran Latif, \\ ${ }^{2}$ Ismail Abdul Rahman and ${ }^{3}$ Muhammad Yusof Ismail \\ ${ }^{1}$ Faculty of Mechanical and Manufacturing Engineering, \\ ${ }^{2}$ Faculty of Civil and Environmental Engineering, \\ ${ }^{3}$ Faculty of Electrical and Electronic Engineering, \\ UTHM, 86400 Parit Raja, Johor, Malaysia
}

\begin{abstract}
Problem statement: Concrete is basic construction material used for most of structures. However, the typical vital structures have to be designed as self-protective such as nuclear plants, power plants, weapon industries, weapons storage places and water retaining structures, against any threats like natural disaster tragedy incident or intentionally produced by horrible incidents such as dynamic loading, incident occurs in nuclear plants, terrorist attack, missile attack tsunami and etc. Approach: In modern science, the impact energies are crucial way to study the local impact effects on concrete structures. Results: The way in which the kinetic energy is distributed through the concrete target is also noteworthy in determining its response, with the influence of dimensional analysis of the non dimensional numbers. This study is concentrate on development of empirical formula for predicting penetration depth of ogive nose hard missile in to the concrete structures, with the effects of different $\mathrm{CRH}$ ratios of missile $(\mathrm{CRH}=2.0, \mathrm{CRH}=3.0, \mathrm{CRH}=4.5, \mathrm{CRH}=6.0)$ based on critical impact energies, by using curve fitting dimensional analysis of non-dimensional numbers. Conclusions/Recommendations: For the verification, the proposed developed empirical formula was compared with other established formulae such as Modified NDRC formula, Hughes formula, ACE formula, UKAEA formula. It is expected that the outcome of the proposed formulae can be applied in design recommendations and design procedures, especially for determining the dynamic reaction of the target to foil penetration in terms of critical impact kinetic energy.
\end{abstract}

Key words: Penetration, Local impact, kinetic energy, concrete, empirical, ogive nose, hard missile, $\mathrm{CRH}$

\section{INTRODUCTION}

The effects of the local impact of hard missile on structures have been studied since the mid of 17th century because of incessant military attention in designing of high performance missiles and high performance defensive obstructions (Li et al., 2005). Concrete is commonly used construction material for the self-protective and civil applications to protect structures from local and explosive impact loads. A review uncovered that peak studies about concrete structures against dynamic loading were conducted from the early 1940s (Wang et al., 2007). However, shortly after World War-II most of the research work ceased and were not resumed until 1960s (Wang et al., 2007). Since five decades ago, intensive study on the local impact effects of hard missiles on concrete targets re- initiated by Kennedy in 1976 and provided an early review of the concrete design against missile local impact effects for nuclear industry. Various studies have been conducted to specify the local impact effects of hard missile on concrete structures, which were discussed intensively in previous publications, e.g., (Kennedy, 1976) and (Li 2005).

In general, the local impact effect of hard missile on concrete structures can be studied in three ways, (i) empirical study (predict empirical formula based on experimental data), (ii) analytical study (create formula based on physical laws) and (iii), numerical simulation (based on computer based material model). Empirical formulae are evenly imperative in this field because of complexity of local impact effects phenomena. These empirical formulae created with the help of

Corresponding Author: Ahmad Mujahid Ahmad Zaidi, Faculty of Mechanical and Manufacturing Engineering, UTHM, 86400, Parit Raja, Batu Pahat, Malaysia 
experimental data by curve-fitting. Most empirical formulae are unit dependent and have limited validity of range and strictly can be used within the limits of tests from which formula was established (Kennedy, 1976; Li et al., 2005; Li and Chen, 2003). Extensive empirical studies were conducted in past for penetration, the most used empirical formulae for designing of concrete structures against penetration of hard missile are Modified Petry formula, Ballistic Research Laboratory (BRL) formula, Army Corps of Engineers (ACE) formula, Modified NDRC formula (Kennedy, 1976; Li et al., 2005). Other than these Ammann and Whitney formula for penetration of explosively generated small fragments, Whiifen formula for penetration of reinforced concrete against small fragments, Kar's formula based on young's modulus, UKAEA formula based on Barr's assumptions, Hughes formula based on tensile strength of concrete and Healy and Weissman formula also can be used to predict penetration for concrete targets (Li et al., 2005). Furthermore, Haldar-Hamieh formula based on impact factor, Adeli-Amin formula and IRS formula are used to predict penetration depth of concrete (Li et al., 2005).

Kinetic energy is essential technique to determine the local impact effects. It is essential to determine the effects of kinetic energy on local impact effect in a dimensional analysis of non-dimensional numbers (Li et al., 2006). The critical impact kinetic energy, which can produce maximum penetration without rear face effect in to the concrete target with the impact of hard missile, can be calculated by using empirical formula derived by UMIST (Li et al., 2005). However, literature shows that there are very little work has been done on critical impact kinetic energies regarding penetration depth. Among above all formulae the NDRC formula has vast history of recommendation of more practical predictions among all other formulae (Kennedy, 1976; Li et al., 2005).

Therefore in this study the interest is focused on prediction of penetration depth of concrete target caused by ogive nose hard missile in terms of critical impact energies with different $\mathrm{CRH}$ ratios by the influence of the dimensional analysis of nondimensional numbers.

Hard projectile and soft projectile: The projectile may be classified as 'Hard' and 'Soft' depending upon deformability of projectile with respect to target's deformation. Deformation of hard missile is considerable smaller or negligible as compared with target's deformation. Almost in all cases hard missiles are considered as non-deformable or rigid.
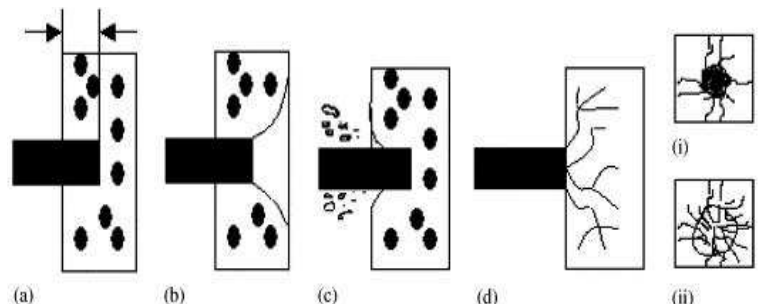

(c)

(d)

(ii)
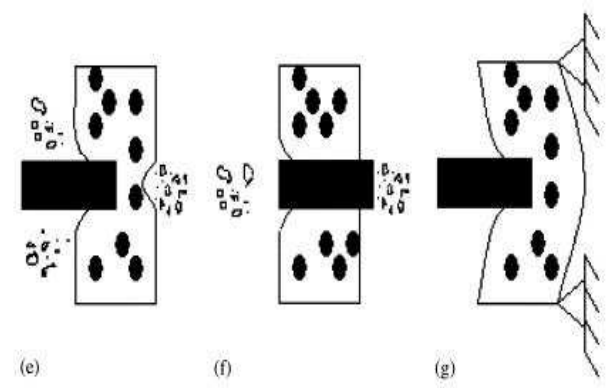

Fig. 1: Explains the local impact phenomena caused by hard projectile. (a) Penetration; (b) cone cracking and plugging; (c) spelling; (d) radial cracking; (e) scabbing; (f) perforation and (g) global impact phenomena (Li et al., 2005)

However, 'Soft' missile deforms itself considerably well as compared to target's deformation (Kennedy 1976), (Li et al., 2005) and (Koechlin and Potapov, 2009).

Local impact: Local impact effect is briefly subdivided in below explained processes (Fig. 1):

Radial cracking: When projectile colloids with concrete target with certain velocity, it results radial cracks originated from the point of impact within the target in every direction (Li et al., 2005).

Spalling: The ejection of material of target from front face (impacted face) due to impact of hard projectile is called spelling. Spelling produces spall crater in the surrounding area of impact. Spall crater is the total damaged portion of peeling off material from target on impacted face (Kennedy, 1976) and (Li et al., 2005).

Penetration: Penetration is defined as the digging of missile into the target body afar from the thickness of spall crater. The lengthwise measurement of dig is called penetration depth (Kennedy, 1976) and (Li et al., 2005).

Cone cracking and plugging: During penetration missile colloids with rear border of target and generates curved shear cracks in the shape of bell plug is called 
cone cracking. And than missile continues penetrating through target, it forces plug and shears-off the surrounding material of target is called plugging. This process generates rapid change into the behavior of target (Li et al., 2005).

Scabbing: Ejection of target material from back face of target is called scabbing (Kennedy, 1976) and (Li et al., 2005).

Perforation: Perforation means complete passage or complete crossing of projectile through the target. It causes missile to extend penetration hole through scabbing crater and exit from the rear face of target (Kennedy, 1976) and (Li et al., 2005).

\section{MATERIALS AND METHODS}

Projectile exists in a long range with variation in sizes, shapes, velocity and weight, density, nose shape, angle of striking, modulus of elasticity and the resistance of concrete relies on concrete density, aggregate size and gradation, aggregate material, concrete compressive and tensile strength, modulus of elasticity, type of reinforcement and reinforcement ratio. The dependent properties of concrete and projectile on which this analysis were conducted are:

Projectile: $2 \leq \mathrm{CRH} \leq 6,0.0642 \leq$ Mass of projectile $(\mathrm{kg}) \leq 13.158,139.30 \leq$ Velocity of projectile $(\mathrm{m} / \mathrm{sec}) \leq$ $1225,12.92 \leq$ Dia. of projectile $(\mathrm{mm}) \leq 76.20$.

Concrete: $1960 \leq$ Density of concrete $\left(\mathrm{kg} \mathrm{m}^{-3}\right) \leq 2370$, $13.5 \leq$ Unconfined compressive strength of concrete $\mathrm{f}_{\mathrm{c}}$ (Mpa) $\leq 108.30,20.197 \leq$ Modulus of elasticity E (Gpa) $\leq 39.55$.

Methodology: It is important to consider the mechanics of the impact processes and thus deduce the relevant non-dimensional numbers that could be involved in penetration depth analyses.

When a non-deformable, projectile strikes with a concrete target, the impact stress on projectile-target interface is well beyond the compressive strength of the target, which leads to the occurrence of penetration process. Therefore, the dependence of the penetration depth can be generally expressed by (Li et al., 2005; 2006; Li and Chen, 2003):

$x=f\left(M, V_{o}, d, N^{*}, \rho_{c}, f_{c}, f_{t}, E_{c}, a, r, \mu_{m}\right)$

Where:

$$
\begin{aligned}
\rho_{\mathrm{c}}, \mathrm{E}_{\mathrm{c}} \text { and } \mathrm{f}_{\mathrm{c}} \text { and } \mathrm{f}_{\mathrm{t}}= & \text { The density, Young's modulus } \\
& \text { and unconfined compressive } \\
& \text { strength (stress) of the concrete } \\
& \text { target, respectively } \\
= & \text { The characteristic size of the } \\
& \text { aggregate } \\
= & \text { The average amount of } \\
& \text { reinforcement in percentage }(\% \\
\mathrm{a} & \text { EWEF) } \\
\mathrm{r} & \text { The sliding friction coefficient } \\
& \text { between the projectile and the } \\
& \text { concrete during penetration } \\
= & \text { The mass and the initial impact } \\
\mu_{\mathrm{m}} & \text { velocity of a projectile } \\
= & \text { The (cylindrical) projectile shank } \\
\mathrm{M} \text { and } \mathrm{V}_{\mathrm{o}} & \text { diameter } \\
\mathrm{d} & \text { "Nose shape factor" }
\end{aligned}
$$

The required critical impact energy for penetration can be expressed by:

$\frac{E_{c p}}{f_{c} d^{3}}=G\left(\frac{M}{\rho d^{3}}, \frac{f_{t}}{f_{c}}, \frac{E}{f_{c}}, \frac{\tau_{f}}{f_{c}}\right)$

Where:

$\mathrm{E}_{\mathrm{c}} \quad=1 / 2 \mathrm{MV}_{\mathrm{c}}^{2}$

$\mathrm{f}_{\mathrm{t}} / \mathrm{f}_{\mathrm{c}}$ and $\mathrm{E} / \mathrm{f}_{\mathrm{c}}=$ Constants

A non-dimensional analysis for penetration of concrete targets based on Eq. 1 leads to:

$\frac{x}{d}=G\left(\frac{E_{k}}{f_{c} d^{3}}, \frac{M}{\rho d^{3}}, \frac{f_{t}}{f_{c}}, \frac{E}{f_{c}}, \frac{\tau_{f}}{f_{c}}\right)$

where, $E_{k}=(1 / 2) M_{o}^{2}$ is the kinetic energy of the missile. Although the penetration is normally selected as a design parameter in empirical formulae, when rear boundary effects are neglected in the penetration analysis, no geometrical dimension of concrete thickness needs to be introduced (Li et al., 2005; 2006; $\mathrm{Li}$ and Chen, 2003).

Empirical prediction: The proposed empirical formula for calculation of penetration depth of ogive nose hard missile into concrete structures with $\mathrm{CRH}=2.0, \mathrm{CRH}$ $=3.0, \mathrm{CRH}=4.5, \mathrm{CRH}=6.0$ based on kinetic energies is developed by using the linear equations.

The basic linear eq. for straight line is:

$y=m x+b$ 
A empirical relationship have been developed between CRH value of projectile and co-efficient (m) and (b) by using curve fitting polynomial equation:

$$
\mathrm{m}=0.014 \mathrm{CRH}^{3}-0.1585 \mathrm{CRH}^{2}+0.5606 \mathrm{CRH}-0.5405
$$

and

$\mathrm{b}=-0.6256 \mathrm{CRH}^{3}+7.9656 \mathrm{CRH}^{2}-32.892 \mathrm{CRH}+48.008(6)$

Based on Eq. 4 the general equation for penetration depth based on critical impact kinetic energy in to the concrete target is:

$\frac{x}{d}=m \frac{E_{c p}}{f_{c} d^{3}}+b$

Where

$\mathrm{E}_{\mathrm{cp}}=$ Kinetic impact kinetic energy of missile for penetration of concrete target

$\mathrm{f}_{\mathrm{c}}=$ Unconfined compressive stress of concrete

$\mathrm{d}=$ (Cylindrical) projectile shank diameter

Based on Eq. 5-7 penetration depth of ogive nose hard missile into concrete structures with $\mathrm{CRH}=2.0$, $\mathrm{CRH}=3.0, \mathrm{CRH}=4.5, \mathrm{CRH}=6.0$ are:

For $\mathrm{CRH}=2.0$ :

$\frac{x}{d}=0.0592 \frac{E_{c p}}{f_{c} d^{3}}+9.0807$

For $\mathrm{CRH}=3.0$ :

$$
\frac{\mathrm{x}}{\mathrm{d}}=0.0941 \frac{\mathrm{E}_{\mathrm{cp}}}{\mathrm{f}_{\mathrm{c}} \mathrm{d}^{3}}+4.1294
$$

For $\mathrm{CRH}=4.25$ :

$$
\frac{x}{d}=0.0571 \frac{E_{c p}}{f_{c} d^{3}}+4.0675
$$

And for $\mathrm{CRH}=6.0$ :

$$
\frac{x}{d}=0.1495 \frac{E_{c p}}{f_{c} d^{3}}+2.2802
$$

The above non-dimensional Eq. 8-11 can be used within there applicable given range depend on $\frac{E_{c p}}{f_{c} d^{3}}$.

\section{RESULTS}

The proposed formula was examined for the prediction of penetration depth of ogive nose hard missile into concrete structures with $\mathrm{CRH}=2.0$, $\mathrm{CRH}=3.0, \mathrm{CRH}=4.5, \mathrm{CRH}=6.0$ based on kinetic energy. Results obtained from proposed formula are relatively closer as compared to the experimental results (Fig. 2-5).

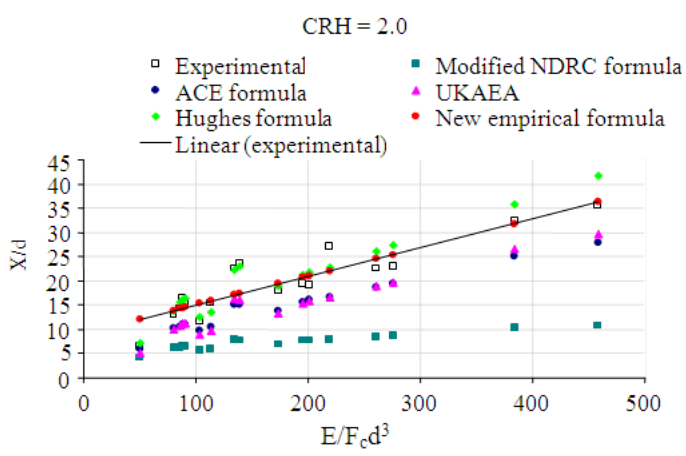

Fig. 2: The results of newly developed formula and comparison with prediction of other formulae for $\mathrm{CRH}=2.0$

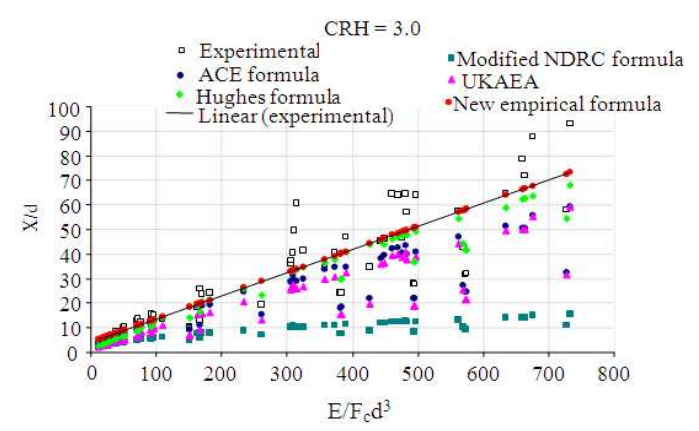

Fig. 3: The results of newly developed formula and comparison with prediction of other formulae for $\mathrm{CRH}=3.0$

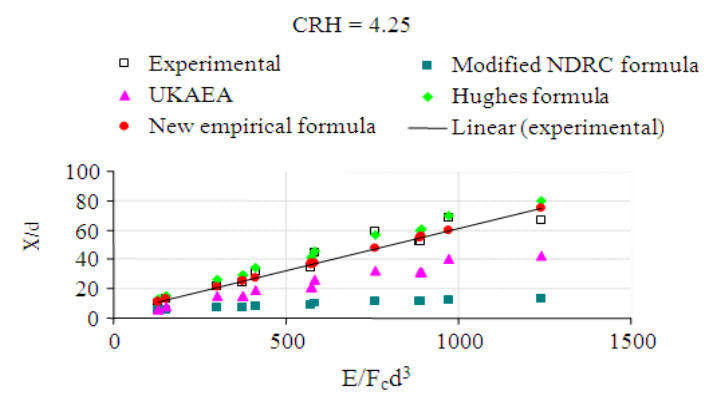

Fig. 4: The results of newly developed formula and comparison with prediction of other formulae for $\mathrm{CRH}=4.25$ 
Am. J. Applied Sci., 7 (5): 711-716, 2010

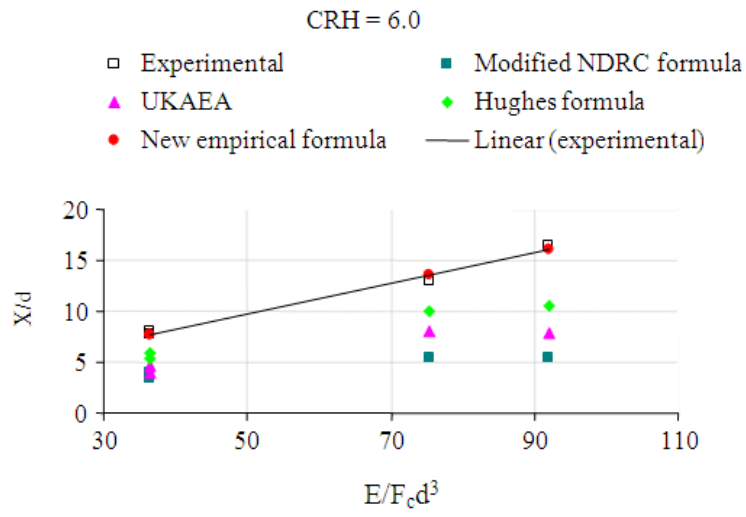

Fig. 5: The results of newly developed formula and comparison with prediction of other formulae for $\mathrm{CRH}=6.0$

The Eq. 5 and 6 can be used for finding equation constants ( $\mathrm{m}$ and $\mathrm{b}$ for Eq. 7) based on $\mathrm{CRH}$ value relationship of non-dimensional analysis for predicting the penetration depth within the range of $2.0 \leq \mathrm{CRH} \leq 6.0$.

\section{DISCUSSION}

The main predicted results based on new empirical formulae have been compared with the experimental data and results obtained from Modified NDRC Formula, UKAEA Formula, Hughes formula and ACE Formula for $\mathrm{CRH}=2.0,3.0,4.25$ and 6.0 are summarized here. It is found that the Modified NDRC formula predicts the lowest values compared with other three groups of empirical formulae. The predicted results are consistently lower than the experimental results. Although overall predictions based on Hughes Formula are closer to experimental data than those based on other formulae, the Hughes formula sometimes overestimate the penetration depth prediction.

Among all these four formulae the newly developed formula gives relatively average results as compared to other formulae. Like Hughes formula the newly developed formula also sometimes gives over prediction results.

Limitations: Most of empirical formulae for the prediction of local impact effects of hard missile on concrete targets have their specific range of parameters and the validity of those empirical formulae are only guaranteed in their application range. Like other empirical formulae, this formula also can be used within the certain range:
For $\mathrm{CRH}=2.0$ :

$2340 \leq$ Density $\leq 2370\left(\mathrm{~kg} \mathrm{~m}^{-3}\right), 32.4 \leq \mathrm{f}_{\mathrm{c}} \leq 108.30(\mathrm{MPa})$, $0.898 \leq \mathrm{M} \leq 0.912(\mathrm{~kg}), 277 \leq \mathrm{V}_{\mathrm{o}} \leq 800\left(\mathrm{~m} \mathrm{sec}^{-1}\right)$, $27.04 \leq \mathrm{E} \leq 39.55$ (Gpa), for normal impact

$$
\text { For } \mathrm{CRH}=3.0 \text { : }
$$

$1960 \leq$ Density $\leq 2320\left(\mathrm{~kg} \mathrm{~m}^{-3}\right), 13.5 \leq \mathrm{f}_{\mathrm{c}} \leq 62.80(\mathrm{MPa})$, $0.0642 \leq \mathrm{M} \leq 13.158(\mathrm{~kg}), 139.30 \leq \mathrm{V}_{\mathrm{o}} \leq 1225\left(\mathrm{~m} \mathrm{sec}^{-1}\right)$, $20.197 \leq \mathrm{E} \leq 33.71$ (Gpa), for normal impact

$$
\text { For } \mathrm{CRH}=4.25 \text { : }
$$

$1960 \leq$ Density $\leq 2000\left(\mathrm{~kg} \mathrm{~m}^{-3}\right), 13.5 \leq \mathrm{f}_{\mathrm{c}} \leq 21.60(\mathrm{MPa})$, $0.064 \leq \mathrm{M}(\mathrm{kg}) \leq 0.0642,345 \leq \mathrm{V}_{\mathrm{o}} \leq 1190\left(\mathrm{~m} \mathrm{sec}^{-1}\right)$, $20.197 \leq \mathrm{E} \leq 23.623$ (Gpa), for normal impact

For $\mathrm{CRH}=6.0$ :

$2040 \leq$ Density $\leq 2250\left(\mathrm{~kg} \mathrm{~m}^{-3}\right), 23 \leq \mathrm{f}_{\mathrm{c}} \leq 39(\mathrm{MPa})$, $12.873 \leq \mathrm{M} \leq 13.064(\mathrm{~kg}), 312.50 \leq \mathrm{V}_{\mathrm{o}} \leq 448.50\left(\mathrm{~m} \mathrm{sec}^{-1}\right)$, $24.123 \leq \mathrm{E} \leq 28.766$ (Gpa), for normal impact

\section{CONCLUSION}

The influence of the dimensional analysis of nondimensional numbers based on critical impact energies, at which penetration occurs in concrete targets may be initiated by ogive nose hard missile with CRH value of 2.0, 3.0, 4.25 and 6.0, has been investigated in this study. A new empirical formula for penetration depth based on critical impact kinetic energies of concrete target, has been developed. The results obtained from new formula are also compared with other empirical formulae likes of UKAEA, Modified NDRC, ACE and Hughes formulae. Since NDRC formulae have a long history and wide range of applications and it is recommended as the most appropriate formulae for the preliminary impact design of concrete targets in nuclear facilities. However the results obtained from proposed formula shows relatively average predictions, as compared to other formulae and sometimes over predicted. Therefore, appropriate safety factor should be considered for the design application.

\section{REFERENCES}

Li, Q.M. and X.W. Chen, 2003. Dimensionless formulae for penetration depth of concrete target impacted by a non-deformable projectile. Int. J. Impact Eng., 28: 93-116. DOI: 10.1016/S0734$743 x(02) 00037-4$ 
Li, Q.M., S.R. Reid, H.M. Wen and A.R. Telford, 2005. Local impact effects of hard missiles on concrete targets. Int. J. Impact Eng., 32: 224-284. DOI: 10.1016/j.ijimpeng.2005.04.005

Li, Q.M., S.R. Reid and A.M. Ahmad-Zaidi, 2006. Critical impact energies for scabbing and perforation of concrete target. Nucl. Eng. Des., 236: 1140-1148.

DOI: 10.1016/j.nucengdes.2005.10.017

Kennedy, R.P., 1976. A review of procedures for the analysis and design of concrete structures to resist missile impact effects. Nucl. Eng. Des., 37: 183-203. DOI: 10.1016/0029-5493(85)90165-7
Koechlin, P. and S. Potapov, 2009. Classification of soft and hard impacts-application to aircraft crash. Nucl. Eng. Des., 239: 613-618.DOI: 10.1016/J.NUCENGDES.2008.10.016

Wang, Z.L., Y.C. Li, R.F. Shen and J.G. Wang, 2007. Numerical study on craters and penetration of concrete slab by ogive nose steel projectile. Comput. Geotech., 36: 1-9. DOI: 10.1016/J.COMPGEO.2006.09.001 